\title{
Tracking diet variety in childhood and its association with eating behaviours related to appetite: The generation XXI birth cohort
}

\author{
Sofia Vilela ${ }^{\text {a, * }}$, Marion M. Hetherington ${ }^{\text {b }}$, Andreia Oliveira ${ }^{\text {a, c }}$, Carla Lopes ${ }^{\text {a, c }}$ \\ a EPIUnit - Instituto de Saúde Pública, Universidade do Porto, Rua das Taipas, $n^{\circ} 135$, 4050-600 Porto, Portugal \\ ${ }^{\mathrm{b}}$ School of Psychology, University of Leeds, Leeds, LS2 9JT, England, UK \\ ${ }^{\mathrm{c}}$ Departamento de Ciências da Saúde Pública e Forenses, e Educação Médica, Faculdade de Medicina, Universidade do Porto, Alameda Prof. Hernâni \\ Monteiro, 4200-319 Porto, Portugal
}

\section{A R T I C L E I N F O}

\section{Article history:}

Received 10 October 2017

Received in revised form

31 December 2017

Accepted 31 December 2017

Available online 4 January 2018

\section{Keywords:}

CEBQ

Appetite

Children

Cohort studies

Diet variety

Tracking

\begin{abstract}
A B S T R A C T
Research on the influence of early eating habits on eating behaviours related to appetite using a prospective approach is scarce, especially in children. The aim of this study was to explore the relationship between changes in diet variety from 4 to 7 years of age and appetitive traits measured at 7 years of age. Participants are from the population-based birth cohort Generation XXI (2005-2006). The present analysis included 4537 children with complete data on a food frequency questionnaire (FFQ) at both ages, and on the Children's Eating Behaviour Questionnaire at 7y. A healthy diet variety index (HDVI) was calculated at both ages using data from the FFQ. To assess tracking of diet variety, tertiles of HDVI scores were calculated and then re-categorized as 'maintain: low', 'maintain: high', 'increase' and 'decrease'. Although the HDVI score decreased from 4 to $7 \mathrm{y}(\mathrm{p}<.001)$, it showed a high stability, a positive predictive value, and a fair agreement. Increasing diet variety, compared to maintaining a low variety, was inversely associated with the 'Desire to Drink' ( $\beta=-0.090,95 \% \mathrm{CI}: 0.174 ;-0.006)$ and 'Satiety Responsiveness' ( $\beta=-0.119,95 \% \mathrm{CI}$ : $0.184 ;-0.054)$ subdimensions and positively with 'Enjoyment of Food' ( $\beta=0.098,95 \% \mathrm{CI}: 0.023 ; 0.172)$ and 'Emotional Overeating' ( $\beta=0.073,95 \% \mathrm{CI}: 0.006 ; 0.139)$. Those classified as either increase or maintain a high diet variety, in comparison with maintaining a low variety, had lower scores of 'Food Fussiness'. In conclusion, diet variety decreased from 4 to $7 \mathrm{y}$ with a fair tracking. Children with a higher diet variety were less fussy, had a lower desire to drink and a higher general interest in food.
\end{abstract}

(c) 2018 Elsevier Ltd. All rights reserved.

\section{Introduction}

Eating behaviour patterns acquired during childhood and adolescence are likely to track into adulthood (Mikkila, Rasanen, Raitakari, Pietinen, \& Viikari, 2004, 2005). Diet tracking might be represented by the maintenance of eating habits, nutrient intake or food intake over time. Poor eating habits established in early life are likely to remain stable, therefore establishing healthy eating habits early on is essential. Dietary tracking has been demonstrated in adults and between adolescence and adulthood period, while few studies have tracked diet during childhood (Northstone \& Emmett, 2008). It has been shown that the introduction of a variety of foods

Abbreviations: HDVI, Healthy Diet Variety Index.

* Corresponding author.

E-mail address: sofia.vilela@ispup.up.pt (S. Vilela). as early as the beginning of the complementary feeding, positively influences the variety of the diet later on (Maier, Chabanet, Schaal, Leathwood, \& Issanchou, 2008; Skinner, Carruth, Bounds, Ziegler, \& Reidy, 2002). Variety of the free food choices between 2 and 3 years has been associated with the variety of food consumed up to the age of 22 years (Nicklaus, Boggio, Chabanet, \& Issanchou, 2005). Several paediatric diet quality indices, including assessment of the food variety, have been administered in both developed and developing countries and studied in relation to health-related outcomes (Marshall, Burrows, \& Collins, 2014). However, the tracking of the overall food variety throughout childhood, using the same validated instrument, is lacking in the literature.

An earlier study has proposed that other aspects of eating behaviour, such those related to appetite, also track throughout childhood (Ashcroft, Semmler, Carnell, van Jaarsveld, \& Wardle, 2008). The authors highlighted that some changes in the magnitude of appetitive traits can, however, occur as the result of 
interaction with child's food environment (Mallan, Fildes, Magarey, \& Daniels, 2016; de Barse et al., 2017). One aspect previously explored was the decrease of food fussiness behaviour with an increase of diet variety offered to children (Mallan et al., 2016; de Barse et al., 2017).

Recommendations (WHO, 1996) to increase the diet variety in order to achieve a higher quality diet are included in most European national dietary guidelines, including Portugal (WHO European Region, 2003). The term 'diet variety' indicates the number of different foods or food groups consumed over a given reference period. Increasing the variety of nutrient-dense foods, within and across food groups, is thought to ensure adequate intake of essential nutrients and to improve health outcomes (Conklin, Monsivais, Khaw, \& Wareham, 2016; Foote, Murphy, Wilkens, Basiotis, \& Carlson, 2004; Murphy et al., 2006; Steyn, Nel, Nantel, Kennedy, \& Labadarios, 2006; Vadiveloo, Parkeh, \& Mattei, 2015). The World Health Organization (WHO) recommends the consumption of a varied diet originated mainly from plants, rather than animals (WHO, 1996). Eating a variety of foods is crucial to achieving optimal nutritional status and complete coverage of essential nutrients. It is also a key factor to tackle chronic micronutrient deficiencies, also known as hidden hunger (Burchi, Fanzo, \& Frison, 2011).

A greater variety of healthy foods has been also associated with a lower prevalence of overweight or obesity (Vadiveloo, Dixon, \& Parekh, 2013). However, intake of a variety of less healthy foods, such as energy-dense foods, has been positively associated with adiposity (Vadiveloo et al., 2013). It is not known whether exposure to a higher food variety environment might stimulate appetite and increase food consumption, leading to excess energy intake and an unhealthy body weight gain. Short-term controlled feeding studies consistently show that the variety of food offered during a meal increases energy intake, and limiting variety across days tends to reduce food consumption (Brondel et al., 2009; Raynor \& Epstein, 2001). The stimulating effect of a high diet variety on appetite might be attributable to lower sensory-specific satiation for multiple components of a meal, to delayed satiation or by making the eating occasion more enjoyable (Brondel et al., 2009). These shortterm studies are limited by the tendency to offer highly palatable, energy-dense foods. When low energy-dense foods are offered, for example, fruits and vegetables (FV), the variety effect seems to stimulate intake in both children (Roe, Meengs, Birch, \& Rolls, 2013) and adults (Meengs, Roe, \& Rolls, 2012a).

The majority of previous studies have investigated the effects of food variety on appetite using short-term controlled feeding studies, however, to date no published research has investigated the association in children between tracking of diet variety and eating behaviours related to appetite, using a prospective approach. Therefore, we aimed to prospectively assess the effect of changes in diet variety from 4 to 7 years on eating behaviours related to appetite at 7 years of age.

\section{Material and methods}

\subsection{Study design and participants}

Participants were from the population-based birth cohort Generation XXI, assembled in the five-level III public maternity units in the Porto Metropolitan Area (Northern Portugal), during 2005/2006 (Larsen et al., 2013). At enrolment, these maternity units were responsible for $91.6 \%$ of the deliveries in the whole catchment population. Of the invited mothers, $91.4 \%$ accepted to participate at baseline ( $n=8647$ children). Data on demographic and social conditions, lifestyles, medical history and anthropometrics were collected by trained interviewers within $72 \mathrm{~h}$ after delivery. When the children were 4 and 7 years of age, an evaluation of the entire cohort occurred, achieving a participation rate of $86 \%$ and $81 \%$, respectively. In baseline and follow-up evaluations, information was collected in face-to-face interviews, and for those families that were not able to participate in-person, the evaluation was performed by telephone using a shorter version of the questionnaire (20\% and $15 \%$ at 4 and 7 years of age, respectively).

The present analysis included 4748 children with complete data using a food frequency questionnaire (FFQ) (Durao et al., 2015) at 4 and 7 years of age, and complete information on the Children's Eating Behaviour Questionnaire (CEBQ) (Wardle, Guthrie, Sanderson, \& Rapoport, 2001), at 7 years of age. We excluded twins $(n=183)$ and children with congenital anomalies or diseases that might influence dietary intake (cerebral palsy, celiac disease, food allergy, food intolerance, and phenylketonuria; $n=28$ ), resulting in a sample of 4537 children. Comparing the children included in the analysis with the remaining cohort, we found no statistical differences regarding sex children. However, mothers of children included in the study at baseline were slightly older (mean (SD): 29.8 (5.25) vs. 28.1 (5.82) years, $\mathrm{p}<.001$ ) and more educated (mean (SD): $11.2(4.27)$ vs. $9.6(4.10)$ years, $\mathrm{p}<.001)$. The prevalence of obesity in our sample was also higher ( $68 \%$ vs. $67 \%, \mathrm{p}=.009$ ).

\subsection{Data collection}

\subsubsection{Dietary intake}

The children's dietary intake was evaluated through an FFQ that queried frequency of intake for 35 and 38 food items at 4 and 7 years of age, respectively, that was previously tested. As previously described (Durao et al., 2015), for each food item, parents or another caregiver were asked how many times on average his/her child had consumed that food during the previous 6 months.

For each food item, the selected frequency response option (4 times or more per day, 2-3 times per day, 1 time per day, 5-6 times per week, 2-4 times per week, 1 time per week, 1-3 times per month|once a month, or never) was converted into daily frequency (e.g. 5-6 times per week was converted into a mean of 5.5 times per week, meaning $5.5 / 7 d=0.78$ times per day). Five food groups were defined: starchy foods ( 3 original food items: rice, pasta, potatoes, bread and semi-sweet type biscuits); fruits (only one food item); vegetables (3 original food items: vegetable soup and vegetable on plate); meat, fish and alternatives (5 original food items: meat, sausage, ham, fish and eggs); and dairy products (5 original food items at $4 \mathrm{y}$ and 4 food items at $7 \mathrm{y}$ : yoghurt, cheese and milk).

In a subsample of 2482 children at 4 years and 3511 at 7 years, FFQ data was compared with 3-day food diaries. For food groups eaten more often, fair-to-moderate agreement was obtained. Significant positive intraclass correlation coefficients (ICC) were found for vegetable soup $[(\mathrm{ICC}=0.54,95 \% \mathrm{CI}: 0.51 ; 0.56)$ at 4 years and (ICC $=0.54,95 \% \mathrm{CI}: 0.52 ; 0.56)$ at 7 years $]$, fruit $[(\mathrm{ICC}=0.42,95 \% \mathrm{CI}$ : $0.39 ; 0.45$ ) at 4 years and (ICC $=0.46,95 \% \mathrm{CI}: 0.43 ; 0.48$ ) at 7 years], milk [ $(\mathrm{ICC}=0.46,95 \% \mathrm{CI}: 0.43 ; 0.49)$ at 4 years and $(\mathrm{ICC}=0.50,95 \%$ CI: $0.47 ; 0.52)$ at 7 years], yoghurt [(ICC $=0.48,95 \% \mathrm{CI}: 0.45 ; 0.51)$ at 4 years and $(\mathrm{ICC}=0.49,95 \% \mathrm{CI}$ : $0.47 ; 0.52)$ at 7 years], sweets $[(\mathrm{ICC}=0.23,95 \% \mathrm{CI}: 0.19 ; 0.26)$ at 4 years and $(\mathrm{ICC}=0.22,95 \% \mathrm{CI}$ : $0.19 ; 0.25)$ at 7 years] and salty snacks [ $(\mathrm{ICC}=0.19,95 \% \mathrm{CI}: 0.16$; 0.23 ) at 4 years and $(\mathrm{ICC}=0.10,95 \% \mathrm{CI}: 0.07 ; 0.13)$ at 7 years].

\subsubsection{Diet variety index}

A healthy diet variety index (HDVI) (Jones et al., 2015), based on the Food Variety Index for Toddlers by Cox et al. (Cox, Skinner, Carruth, Moran, \& Houck, 1997), was calculated at 4 and 7 years using data from the FFQ. This was done by considering variety within and among the five food groups previously described, and 
considering the number of servings recommended in the food plate model healthy eating guidelines promoted by the U.S. Department of Agriculture (U.S. Department of Agriculture and U.S. Department of Health and Human Services, 2010). As indorsed by Cox et al. (Cox et al., 1997), truncations were applied in the next steps to ensure variety in intake both within and between food groups. As recommended in the original index (Cox et al., 1997), a higher variety of a particular food item or food groups could not compensate a low intake of other food item or food groups. First, within each food groups (except FV) the contribution of a particular food item was truncated at $33 \%$. Foods within a food group, which were similar (e.g. yoghurt without sugar and sweetened yoghurt at 4 years) were grouped together and counted as a single food, so they did not contribute more than $33 \%$ of the total. Due to the relatively limited number of questions of the FFQ, it was not possible to assess variety of FV. For these items, the index instead reflects whether or not the children ate the recommended number of servings. The number of servings for each food group was completed after the groupings and truncations were applied. Food group scores were calculated by dividing the total number of servings by the recommended number of servings per day, for each food group. The following recommended number of servings was used: starchy foods $=7$, fruit $=2$, vegetables $=3$, meat, fish and alternatives $=2$ and dairy foods $=3$. Then, a second truncation was applied to ensure variety between the food groups. Each food group score was truncated at 1 point (e.g. if a child ate 3 different types of meat, fish and alternatives daily when this was divided by 2 it gave a potential score of 1.5 points which was then truncated to 1 point). This meant that a high intake of one food group could not compensate for a low intake of another food group. The final HDVI was the sum of the five food group scores and the maximum score was 5 , representing a higher diet variety and adequacy.

\subsubsection{Children's eating behaviours}

Appetitive traits were assessed using a Portuguese version of the Children's Eating Behaviour Questionnaire - CEBQ originally developed by Wardle et al. (Wardle et al., 2001) which had been previously translated and tested, and shown to have good psychometric properties in 7-year-old Portuguese children (Albuquerque, Severo, \& Oliveira, 2017). This questionnaire is a parental report (94\% of the questionnaires were answered by mothers) constructed to assess eight subdimensions of eating behaviours in children: 'Food Responsiveness' (FR), 'Enjoyment of Food' (EF), Emotional Overeating' (EOE) and 'Desire to Drink' (DD) as 'food-approach' appetitive traits, and 'Satiety Responsiveness' (SR), 'Slowness in Eating' (SE), 'Emotional Undereating' (EUE) and 'Food Fussiness' (FF) as 'food-avoidant' appetitive traits. This 35item instrument is rated on a 5-point Likert scale ("never", "seldom", “sometimes", "often" and "always"), scored 1 to 5. Each of the eight subscales contained 3 to 6 items. The items 3 (SR), 4 (SE), 10 (FF), 16 (FF) and 32 (FF) were reverse-scored items. In individuals with missing data for less than $50 \%$ of the items, missing data (around 3\%) were handled by imputation, replacing the average of the remaining questions within each subdimension.

\subsubsection{Covariates}

Problematic eating behaviours were also assessed at 4 years of age by caregiver report. Caregivers were asked about any perceived eating problem observed in their child. The following questions were included in the final model as potential confounders: "my child does not eat enough", "my child eats very slowly" and "my child eats too much". Caregivers reported if any of these behaviours happened in the last year and their level of concern (very concerned, somewhat concerned, no concern). These variables were used as proxies of the subdimensions of the CEBQ at 4 years of age.
Significant differences were found between different levels of parental concern with children's eating behaviours and scores of the CEBQ subdimensions at 7 years of age (Supplemental Table 1). For example, children with a higher score in 'Enjoyment of Food' and 'Food Responsiveness' were the ones with a higher level of parental concern in "my child eats too much" (9\%). Parents that were more concerned with "not eating enough" (35\%) had children with higher scores in 'Satiety Responsiveness', 'Slowness in Eating' and 'Food Fussiness,' but lower scores in 'Food Responsiveness' and 'Enjoyment of food' ( $\mathrm{p}<.001$, Supplemental Table 1$)$.

Other child and maternal characteristics that may confound the association between diet variety and appetitive traits were also considered. The maternal education was evaluated, at 4-year-old evaluation, as the number of completed school years; the maternal age was obtained as the difference between the date of birth and the date of the 4-year interview. Breastfeeding duration (expressed or directly from the breast) was recorded in weeks, and a variable was defined as any breastfeeding duration (recorded as never or less than 16 weeks, between 16 and 20 weeks and more than 20 weeks). The practice of physical exercise (defined as regular physical exercise) was collected at 4 years of age as a qualitative variable (non-practitioners vs. practitioners). Daily screen time was calculated as the daily minutes spent in front of a screen (television, computer or game devices) during both week and weekend days, and categorized into less than $120 \mathrm{~min}$ and $120 \mathrm{~min}$ or more per day. At 7 years of age, timing of complementary feeding and first food eaten by the infant (cereals porridge (56.9\%), fruit $(5.2 \%)$, vegetable soup $(36.6 \%)$ or other $(1.2 \%)$ ), was recorded and recategorized as 'vegetable soup' vs. 'cereals porridge/fruit/other'. The vegetable soup was separated from the other categories due to the beneficial effect previously described in children having vegetables as the first food, in appetite and acceptance of new foods (Cox et al., 1997; de Barse et al., 2017).

In both evaluations, children's anthropometric measurements were performed by a team of experienced examiners, according to standard procedures. Weight was measured in underwear and without shoes using a digital scale and was recorded to the nearest $0.1 \mathrm{~kg}$. Height was measured as the distance from the top of the head to the bottom of the feet without shoes, using a fixed stadiometer to the nearest $0.1 \mathrm{~cm}$. Children's body mass index (BMI) was classified according to age- and sex-specific BMI standard z-scores developed by WHO (WHO Multicentre Growth Reference Study Group, 2006).

\subsection{Statistical analysis}

Mean (standard deviation) and frequency differences were compared through Student's t-test and chi-square test, respectively. The tracking of behaviours was estimated in different ways, each assessing a specific aspect of tracking. First, tertiles for the score of the HDVI were calculated at 4 and 7 years of age. The proportion of stability was assessed as the proportion of children who remained in the same tertile at both ages divided by the total number of children. If chance alone determined the tertile at age 7 , one third would be expected to be placed in the same tertile; a value higher than 0.33 suggests that children do not stay in the same tertile completely by chance. A predictive value for remaining in the highest tertile was calculated as the proportion of children in the highest tertile at 4 years of age who remained in the highest tertile at 7 years, divided by the children in the highest tertile at 4 who had moved to other tertiles at 7 years. A value higher than 1 suggests more children remained than changed. Confidence intervals were calculated for the predictive value. For testing the overall tracking, the ICC was applied. Guidelines for interpreting ICC statistics suggest that values between 0.81 and 1.00 indicate 
almost perfect agreement, $0.61-0.80$ substantial agreement, $0.41-0.60$ moderate agreement, $0.21-0.40$ fair agreement, and values less than 0.21 indicate a poor or slight agreement (Landis \& Koch, 1977).

The effect size for the HDVI was calculated by dividing the mean change in the score (between 4 and 7 years of age) by the standard deviation (SD) of the initial mean score (at 4 years). Cohen classified effect sizes as small $(d=0.2)$, medium $(d=0.5)$, and large $(d \geq 0.8)$ (Cohen, 1992). Furthermore, tertiles of HDVI score were transformed as following: 'maintain: high', for children who were at 2nd or 3rd tertile in both ages, 'maintain: low', for children who were at 1st tertile at both ages, 'increase', for children whose scores changed to a higher tertile (e.g. 1st tertile to 2 nd or 2 nd to 3 rd) and 'decrease', for children whose scores fell to a lower tertile (e.g. 3rd tertile to 1 st or 3rd to 2 nd).

Associations between tracking behaviour (maintain: high; maintain: low; increase; and decrease - exposure) and appetitive subdimensions of the CEBQ (outcome) were evaluated through linear regression models - regression coefficients and respective $95 \%$ confidence intervals $\left[\beta^{\wedge}, 95 \% \mathrm{CI}\right]$. Two regression models were presented, one crude model and the other model adjusted for maternal age, maternal education (in years) and child's BMI at 4 years (adjusted model). Other potential confounders, such as parental concerns of problematic eating behaviours at 4 years, breastfeeding duration, the practice of physical exercise, daily screen time and the first food eaten, were tested and included in the adjusted model if statistically significant for the model. An interaction of the child's sex in these associations was studied by including an interaction term in the final models, but no significant interaction was found; thus, results are reported for all children.

The software used was the Statistical Package for the Social Sciences (IBM Corp. Released 2011. IBM SPSS Statistics for Windows, Version 22.0. Armonk, NY: IBM Corp.). Significance was established a priori at 0.05 .

\subsection{Ethical consideration}

The project Generation XXI was conducted according to the guidelines laid down in the Declaration of Helsinki and all procedures involving human subjects/patients were approved by the Ethical Committee of the São João Hospital/the University of Porto Medical School. The project was approved by the Portuguese Authority of Data Protection. Parents or legal guardians of each participant received an explanation on the purposes and design of the study and gave written informed consent at baseline and follow-up evaluations.

\section{Results}

\subsection{Participants characteristics}

Table 1 presents characteristics of children and their mothers by age and sex. The sample in this study had $49 \%$ of girls. No significant differences were found for the maternal level of education and age, between girls and boys. At both ages, there were no significant differences between the groups, regarding HDVI score. At 4 years, a higher prevalence of overweight and obesity was observed among girls, in comparison with boys $(\mathrm{p}=.027)$. At 7 years, there were no statistical differences for BMI between girls and boys $(\mathrm{p}=.167)$. However, when comparing between the two periods of time, the HDVI score decreased from 4 to 7 years (mean (SD): 4.01 (0.52) and $3.60(0.35)$, respectively, $\mathrm{p}<.001)$, with a large effect size $(0.8)$. The HDVI score at 4 years ranged from 1.45 to 4.99 and at 7 years from 1.27 to 4.95 (from a possible maximum of 5). From 4 to 7 years of age, for each food group that contributes to the HDVI, a statistically significant $(\mathrm{p}<.001)$ decrease was observed in the frequency of consumption per day. Compared to girls, boys had a higher frequency of intake of starch in both ages. At 7 years, boys had a higher intake of foods from the dairy category than girls [mean (SD): 2.08 (0.61) vs. 2.03 (0.63), $\mathrm{p}=.010]$.

\subsection{Diet variety tracking}

Fig. 1 shows the proportion of children by tertiles of HDVI score at 4 and 7 years of age. More than half of the children that were in the lowest tertile of HDVI score at 4 years remained in the lowest tertile at 7 years. The same trend was observed for the highest tertile. In a subsample with dietary intake evaluated by 3-day food diaries at $4(n=1984)$ and 7 years of age $(n=2779)$, energy intake, macronutrients and fiber intake were compared across HDVI tertiles. The energy intake increased across tertiles of diet variety in both ages [ 1 st tertile vs. 3rd tertile: at 4 years, mean $(\mathrm{SD})=1567$ (297.4) kcal vs. 1682 (291.4) kcal, p <.001; at 7 years, 1792 (364.3) kcal vs. 1842 (314.7) kcal, $\mathrm{p}=.06$ ]. Children with a high diet variety, compared to children in the lowest tertile of variety (3rd vs 1 st tertile of intake) had a significantly higher intake of fiber at 4 years $[$ mean $(\mathrm{SD})=14$ (3.6) g vs. mean $(\mathrm{SD})=12(3.7) \mathrm{g}, \mathrm{p}<.001]$ and at 7 years [mean $(S D)=16(4.0) \mathrm{g}$, vs. mean $(S D)=13(4.0) \mathrm{g}, \mathrm{p}<.001$ ] On the other hand, in both ages, children with the lowest diet variety had a higher intake of total fat, including saturated fat.

Table 2 presents the tracking values for the HDVI score and for each food group included. Overall, the HDVI showed a stability of $48 \%$ and a positive predictive value $(1.13,95 \% \mathrm{CI}: 1.02 ; 1.25)$. Regarding the food groups, the 'fruit and vegetables' group had the highest stability value (0.52) and the highest predictive value (1.30; $95 \% \mathrm{CI}: 1.18,1.44)$. The agreement was moderate for this food group (ICC $=0.464,95 \% \mathrm{CI}: 0.388 ; 0.529$ ). All the other food groups had stability values higher than 0.33 , but negative predictive values. They all had a fair agreement with the exception of meat, fish and alternatives that showed only slight tracking.

\subsection{Diet variety and eating behaviours related to appetite}

The mean scores in the CEBQ subdimensions at 7 years ranged from $1.8(\mathrm{SD}=0.64)$ for ' Emotional Overeating' to $3.0(\mathrm{SD}=0.80)$ for 'Enjoyment of Food' (Supplemental Table 1).

Associations between levels of tracking of the HDVI (exposure) and eating behaviours related to appetite at 7 years (outcome) are shown in Table 3. Parental concerns for problematic behaviours were used at 4 years as a proxy of appetitive traits. and were tested in the final model as potential confounders.

In the adjusted models, increasing diet variety from 4 to 7 years, in comparison with maintaining a low variety, was inversely associated with the 'Desire to Drink' $(\beta=-0.090,95 \%$ CI: $-0.174 ;-0.006)$ and 'Satiety Responsiveness' ( $\beta=-0.119,95 \%$ CI: $-0.184 ;-0.054)$ subdimensions, and positively with the 'Enjoyment of Food' ( $\beta=0.098,95 \% \mathrm{CI}$ : $0.023 ; 0.172)$ and 'Emotional Overeating' ( $\beta=0.073,95 \% \mathrm{CI}$ : $0.006 ; 0.139$ ). Increase or maintain a high diet variety, in comparison with maintaining a low variety, were associated with lower scores in the 'Food Fussiness'. No effect of changes in HDVI score from 4 to 7 years was observed on 'Food Responsiveness', 'Slowness in Eating', and 'Emotional Undereating'.

\section{Discussion}

To our knowledge, this is the first study assessing the tracking of diet variety from preschool to school age and its association with individual differences in appetitive traits. It is important to know which children will benefit most from practical and targeted interventions to promote healthy diets in early life. The results of this 
Table 1

Sample characteristics by age and sex.

\begin{tabular}{|c|c|c|c|c|c|c|c|c|}
\hline & \multirow[t]{2}{*}{ all } & \multicolumn{3}{|l|}{4 years } & \multirow[t]{2}{*}{ all } & \multicolumn{3}{|l|}{7 years } \\
\hline & & Girls & Boys & p-value & & Girls & Boys & p-value \\
\hline Maternal level of education at $4 y$ (years), mean (SD) & $11.4(4.22)$ & $11.4(4.24)$ & $11.4(4.21)$ & $.320^{\mathrm{a}}$ & - & - & - & - \\
\hline Maternal age at $4 y$ (years), mean (SD) & $34.2(5.22)$ & $34.2(5.32)$ & $34.1(5.15)$ & $.065^{\mathrm{a}}$ & - & - & - & - \\
\hline \multicolumn{9}{|l|}{ Body Mass Index, n (\%) } \\
\hline Normal/Thinness & $3029(68.3)$ & $1454(66.6)$ & $1575(70.0)$ & $.027^{\mathrm{b}}$ & $2754(63.1)$ & $1375(61.9)$ & $1481(64.2)$ & $.167^{\mathrm{b}}$ \\
\hline Overweight & $966(21.8)$ & $493(22.6)$ & $473(21.0)$ & & $940(21.5)$ & $504(22.7)$ & $472(20.5)$ & \\
\hline Obese & $438(9.9)$ & $237(10.9)$ & $201(8.9)$ & & $669(15.3)$ & $344(15.5)$ & $353(15.3)$ & \\
\hline Fruit \& Vegetables, (frequency/day), mean (SD) & $5.09(1.739)$ & $5.12(1.739)$ & $5.08(1.740)$ & $.355^{\mathrm{a}}$ & $4.54(1.648)^{* *}$ & $4.54(1.641)$ & $4.53(1.656)$ & $.732^{\mathrm{a}}$ \\
\hline Starch, (frequency/day), mean (SD) & $5.04(1.114)$ & $5.00(1.145)$ & $5.07(1.141)$ & $.037^{\mathrm{a}}$ & $4.62(1.100)^{* *}$ & $4.54(1.127)$ & $4.69(1.068)$ & $<.001^{\mathrm{a}}$ \\
\hline Dairy, (frequency/day), mean (SD) & $2.31(0.480)$ & $2.31(0.485)$ & $2.31(0.475)$ & $.706^{\mathrm{a}}$ & $2.05(0.618)^{* * *}$ & $2.03(0.628)$ & $2.08(0.607)$ & $.010^{\mathrm{a}}$ \\
\hline Meat, fish and alternatives, (frequency/day), mean (SD) & $1.80(0.320)$ & $1.81(0.324)$ & $1.80(0.316)$ & $.317^{\mathrm{a}}$ & $1.42(0.241)^{* *}$ & $1.42(0.241)$ & $1.41(0.242)$ & $.396^{\mathrm{a}}$ \\
\hline HDVI score, mean (SD) & $4.01(0.521)$ & $4.02(0.519)$ & $4.01(0.522)$ & $.745^{\mathrm{a}}$ & $3.60(0.352)^{* *}$ & $3.58(0.601)$ & $3.61(0.58)$ & $.122^{\mathrm{a}}$ \\
\hline \multicolumn{9}{|l|}{ HDVI stability } \\
\hline Maintain: low $(\mathrm{n}=781)$ & $3.34(0.375)$ & $3.34(0.378)$ & $3.34(0.373)$ & $.881^{\mathrm{a}}$ & $2.83(0.396)$ & $2.81(0.400)$ & $2.86(0.391)$ & $.117^{\mathrm{a}}$ \\
\hline Maintain: high $(n=1397)$ & $4.36(0.291)$ & $4.36(0.294)$ & $4.36(0.288)$ & $.805^{\mathrm{a}}$ & $3.99(0.348)$ & $4.00(0.344)$ & $4.00(0.352)$ & $.531^{\mathrm{a}}$ \\
\hline Increase $(n=1202)$ & $3.73(0.396)$ & $3.72(0.400)$ & $3.74(0.400)$ & $.593^{\mathrm{a}}$ & $3.97(0.319)$ & $3.97(0.317)$ & $3.97(0.323)$ & $.792^{\mathrm{a}}$ \\
\hline Decrease $(n=1157)$ & $4.34(0.267)$ & $4.33(0.265)$ & $4.34(0.269)$ & $.580^{\mathrm{a}}$ & $3.26(0.428)$ & $3.23(0.439)$ & $3.29(0.415)$ & $.014^{\mathrm{a}}$ \\
\hline
\end{tabular}

${ }^{a}$ Student's t-test: comparisons between the sexes, for continuous variables. ${ }^{* *}$ Paired $t$-test: comparisons between ages $(\mathrm{p}<.001)$.

b Chi-square: comparisons between the sexes, for categorical variables.

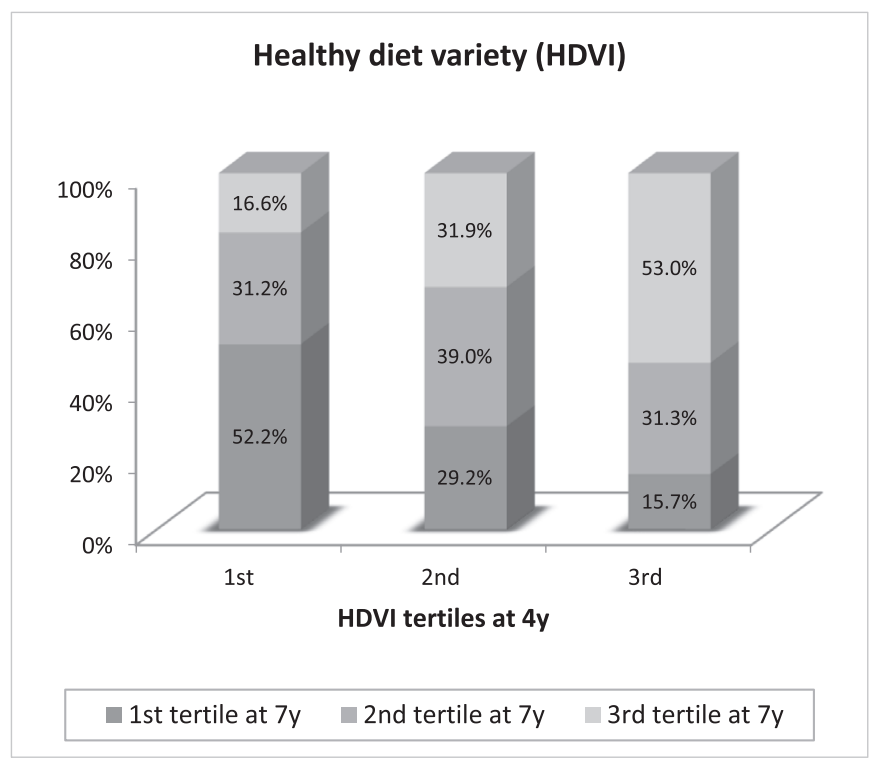

Fig. 1. Proportion of children by tertiles of healthy diet variety index (HDVI) at 4 and 7 years $(\mathrm{y})$ of age.

study show that diet variety is somewhat stable throughout childhood. A higher varied diet, namely through a higher consumption of fruit and vegetables, predicted a fair to moderate tracking during childhood. There is also room for improvement of eating habits since a low tracking was found for the 'starch' and 'meat, fish and alternatives' food groups.

A previous review regarding dietary patterns from childhood to adolescence described a weak to moderate tracking throughout childhood, and between childhood and adolescence periods (Madruga, Araujo, Bertoldi, \& Neutzling, 2012). In a similar birth cohort study (ALSPAC) in the UK, dietary patterns were obtained through early to mid-childhood and stability was assessed. Similar dietary patterns were obtained at 4 and 7 years of age with correlations around 0.60 (Northstone \& Emmett, 2008). A previous study among Brazilian children, and using approximately the same age span, described some level of tracking for diet quality, including diet variety (Rauber, Hoffman, \& Vitolo, 2014). In the present study, although a certain level of tracking was observed from 4 to 7 years, there was a general trend for a decrease in diet variety over time. Further research is warranted to test whether this trend for a decrease in diet variety extends into late childhood. This will be possible to answer with data from Generation XXI, from subsequent follow-up evaluations. Our results are in agreement with previous research, thus early food variety is a predictor of later food variety in childhood but also there is an observed decrease in overall food variety, including fruit and vegetable variety (Nicklaus, 2009). At both ages, almost none of the children reached the recommended score of 5 for the variety of healthy foods. In our sample, although a decrease of consumption of the 'fruit and vegetables' group was described, a higher tracking was observed for this group. However, taking into consideration that we only evaluated recommended eating per day and not fruit and vegetables variety, the tracking might be easier to achieve that using the other food group's variety. Recently, a greater variety of fruit and vegetables was associated with a better overall diet quality in a

Table 2

Tracking values from 4 to 7 years of age of the healthy diet variety index (HDVI) and food groups.

\begin{tabular}{|c|c|c|c|}
\hline & Stability $^{\mathrm{a}}$ & Predictive value $^{\mathrm{b}}$ (95\% CI) & ICC (95\% CI) \\
\hline HDVI & 0.48 & $1.13(1.02,1.25)$ & $0.337(0.104,0.506)$ \\
\hline \multicolumn{4}{|l|}{ Food groups } \\
\hline Fruit \& Vegetables & 0.52 & $1.30(1.18,1.44)$ & $0.464(0.388,0.529)$ \\
\hline Starchy & 0.40 & $0.95(0.85,1.06)$ & $0.209(0.162,0.254)$ \\
\hline Dairy & 0.43 & $0.48(0.42,0.55)$ & $0.307(0.214,0.387)$ \\
\hline Meat, fish and alternatives & 0.39 & $0.85(0.77,0.94)$ & $0.146(-0.051,0.325)$ \\
\hline
\end{tabular}

CI, confidence interval.

a Proportion of children who remained in the same tertile 3 years later.

b Predictive value for remaining in the highest tertile. 
Table 3

Associations between levels of tracking of the healthy diet variety index (HDVI) and eating behaviours related to appetite at 7 years of age.

\begin{tabular}{|c|c|c|c|c|c|c|c|c|}
\hline & \multicolumn{2}{|c|}{ Desire to drink (DD) } & \multicolumn{2}{|c|}{ Enjoyment of Food (EF) } & \multicolumn{2}{|c|}{ Satiety Responsiveness (SR) } & \multicolumn{2}{|c|}{ Slowness in Eating (SE) } \\
\hline & $\begin{array}{l}\text { Crude model } \\
\beta^{\wedge}(95 \% \mathrm{CI})\end{array}$ & $\begin{array}{l}\text { Adjusted model }{ }^{\mathrm{a}} \\
\beta^{\wedge}(95 \% \mathrm{CI})\end{array}$ & $\begin{array}{l}\text { Crude model } \\
\beta^{\wedge}(95 \% \mathrm{CI})\end{array}$ & $\begin{array}{l}\text { Adjusted model }^{\mathrm{b}} \\
\beta^{\wedge}(95 \% \mathrm{CI})\end{array}$ & $\begin{array}{l}\text { Crude model } \\
\beta^{\wedge}(95 \% \mathrm{CI})\end{array}$ & $\begin{array}{l}\text { Adjusted model }^{\mathrm{b}} \\
\beta^{\wedge}(95 \% \mathrm{CI})\end{array}$ & $\begin{array}{l}\text { Crude model } \\
\beta^{\wedge}(95 \% \mathrm{CI})\end{array}$ & $\begin{array}{l}\text { Adjusted model } \\
\beta^{\wedge}(95 \% \mathrm{CI})\end{array}$ \\
\hline \multicolumn{9}{|c|}{ HDVI stability (4 to $7 y$ ) } \\
\hline Maintain: low & ref & ref & ref & ref & ref & ref & ref & ref \\
\hline Maintain: high & $\begin{array}{l}-0.108 \\
(-0.180-0.036)\end{array}$ & $\begin{array}{l}-0.105 \\
(-02300020)\end{array}$ & $\begin{array}{l}0.188 \\
(01170258)\end{array}$ & 0.064 & $\begin{array}{l}-0.185 \\
(-0.245-0.125)\end{array}$ & $\begin{array}{l}-0.074 \\
(-0.1700 .022)\end{array}$ & $\begin{array}{l}-0.076 \\
(-0.153 .0000)\end{array}$ & $\begin{array}{l}-0.017 \\
(-0.1390 .104)\end{array}$ \\
\hline \multirow[t]{2}{*}{ Increase } & -0.108 & -0.090 & 0.174 & 0.098 & -0.186 & -0.119 & -0.095 & -0.031 \\
\hline & $(-0.182,-0.034)$ & $(-0.174,-0.006)$ & $(0.102,0.246)$ & $(0.023,0.172)$ & $(-0.248,-0.124)$ & $(-0.184,-0.054)$ & $(-0.173,-0.016)$ & $(-0.113,0.051)$ \\
\hline \multirow[t]{3}{*}{ Decrease } & $\begin{array}{l}-0.019 \\
(-0.094,0.055)\end{array}$ & $\begin{array}{l}-0.058 \\
(-0.186,0.069)\end{array}$ & $\begin{array}{l}0.173 \\
(0.101,0.246)\end{array}$ & $\begin{array}{l}0.039 \\
(-0.074,0.152)\end{array}$ & $\begin{array}{l}-0.148 \\
(-0.210,-0.085)\end{array}$ & $\begin{array}{l}-0.040 \\
(-0.238,0.058)\end{array}$ & $\begin{array}{l}-0.058 \\
(-0.137,0.021)\end{array}$ & $\begin{array}{l}-0.007 \\
(-0.131,0.118)\end{array}$ \\
\hline & \multicolumn{2}{|c|}{ Food responsiveness (FR) } & \multicolumn{2}{|c|}{ Food fussiness (FF) } & \multicolumn{2}{|c|}{ Emotional Overeating (EOE) } & \multicolumn{2}{|c|}{ Emotional Undereating (EUE) } \\
\hline & $\begin{array}{l}\text { Crude model } \\
\beta^{\wedge}(95 \% \mathrm{CI})\end{array}$ & $\begin{array}{l}\text { Adjusted model }{ }^{\mathrm{b}} \\
\beta^{\wedge}(95 \% \mathrm{CI})\end{array}$ & $\begin{array}{l}\text { Crude model } \\
\beta^{\wedge}(95 \% \mathrm{CI})\end{array}$ & $\begin{array}{l}\text { Adjusted model }{ }^{\mathrm{C}} \\
\beta^{\wedge}(95 \% \mathrm{CI})\end{array}$ & $\begin{array}{l}\text { Crude model } \\
\beta^{\wedge}(95 \% \mathrm{CI})\end{array}$ & $\begin{array}{l}\text { Adjusted model }^{\mathrm{d}} \\
\beta^{\wedge}(95 \% \mathrm{CI})\end{array}$ & $\begin{array}{l}\text { Crude model } \\
\beta^{\wedge}(95 \% \mathrm{CI})\end{array}$ & $\begin{array}{l}\text { Adjusted model } \\
\beta^{\wedge}(95 \% \mathrm{CI})\end{array}$ \\
\hline \multicolumn{9}{|c|}{ HDVI stability (4 to $7 y$ ) } \\
\hline Maintain: low & ref & ref & ref & ref & ref & ref & ref & ref \\
\hline Maintain: high & $\begin{array}{l}0.074 \\
(0.005,0.144)\end{array}$ & $\begin{array}{l}-0.020 \\
(-0.129,0.089)\end{array}$ & $\begin{array}{l}-0.424 \\
(-0.490,-0.358)\end{array}$ & $\begin{array}{l}-0.138 \\
(-0.253,-0.022)\end{array}$ & $\begin{array}{l}0.048 \\
(-0.008,0.105)\end{array}$ & $\begin{array}{l}0.072 \\
(-0.028,0.172)\end{array}$ & $\begin{array}{l}-0.016 \\
(-0.083,0.050)\end{array}$ & $\begin{array}{l}0.006 \\
(-0.110,0.122)\end{array}$ \\
\hline Increase & $\begin{array}{l}0.115 \\
(0.044,0.187)\end{array}$ & $\begin{array}{l}0.057 \\
(-0.016,0.131)\end{array}$ & $\begin{array}{l}-0.325 \\
(-0.392,-0.257)\end{array}$ & $\begin{array}{l}-0.219 \\
(-0.297,-0.141)\end{array}$ & $\begin{array}{l}0.076 \\
(0.019,0.134)\end{array}$ & $\begin{array}{l}0.073 \\
(0.006,0.139)\end{array}$ & $\begin{array}{l}-0.015 \\
(-0.083,0.053)\end{array}$ & $\begin{array}{l}0.007 \\
(-0.071,0.085)\end{array}$ \\
\hline Decrease & $\begin{array}{l}0.130 \\
(0.058,0.202)\end{array}$ & $\begin{array}{l}0.028 \\
(-0.083,0.140)\end{array}$ & $\begin{array}{l}-0.252 \\
(-0.321,-0.184)\end{array}$ & $\begin{array}{l}0.055 \\
(-0.063,0.173)\end{array}$ & $\begin{array}{l}0.073 \\
(0.015,0.132)\end{array}$ & $\begin{array}{l}0.094 \\
(-0.007,0.196)\end{array}$ & $\begin{array}{l}-0.020 \\
(-0.088,0.049)\end{array}$ & $\begin{array}{l}0.018 \\
(-0.101,0.136)\end{array}$ \\
\hline
\end{tabular}

Bold entries denote statistical significance $(\mathrm{p}<.05)$.

a Adjusted for HDVI, maternal age and years of education, children's BMI, caloric intake and parental concern "eating too much" at 4 years.

b Adjusted for HDVI, maternal age and years of education, children's BMI, caloric intake and parental concerns regarding problematic behaviours at 4 years.

c Adjusted for HDVI, maternal age and years of education, children's BMI, caloric intake, weaning first food, and parental concerns "not eating enough" and "eating too slow" at 4 years.

d Adjusted for HDVI, maternal age and years of education, children's BMI, caloric intake, TV per day and parental concern "eating too much" at 4 years.

nationally representative sample of US preschool children (Ramsay, Shriver, \& Taylor, 2017). In another European prospective population-based cohort study (Bjelland et al., 2013), analyzing tracking of food intake from 1 to 7 years of age, fair to moderate tracking was also described for intake of fruit and vegetables. Young children seems to benefit from being exposed consistently to a variety of healthy foods, including fruit and vegetables. In particular, the use of different strategies such as repeated exposure to unfamiliar foods, offering tangible rewards or modifying recipes to improve visual appeal are known to improve intake of healthy foods (Anzman-Frasca, Savage, Marini, Fisher, \& Birch, 2012; Cooke, 2007; Remington, Anez, Croker, Wardle, \& Cooke, 2012).

Diet variety can be evaluated in different ways and there is a lack of consistency in a validated method (Marshall et al., 2014). We used an index based on FFQ previously tested in children from European birth cohorts, including the Generation XXI (Jones et al., 2015; Oliveira et al., 2015). In association with health outcomes, such as obesity, the use of the FFQ is recommended as the most appropriate tool to measure long-term diet variety (SalehiAbargouei, Akbari, Bellissimo, \& Azadbakht, 2016). The comparison between nutrient intake evaluated by food diaries and HDVI tertiles showed a better macronutrient intake profile in children with higher diet variety in both ages.

The effect of diet variety on appetite, mainly related to satiety, has been explored in previous studies. Several authors described a positive effect of offering different types of foods on food intake (Brondel et al., 2009; Bucher, Siegrist, \& van der Horst, 2014; McCrory, Burke, \& Roberts, 2012; Meengs et al., 2012b; Raynor \& Epstein, 2001). For instance, previous studies described that both adults and children ate significantly more vegetables when presented with two or more vegetables, than just one (Bucher et al., 2014; Meengs et al., 2012b). Increasing variety within a meal has been effective in increasing energy intake in older adults with a poor appetite, in a cross-over trial study (Wijnhoven, van der Meij, \& Visser, 2015). Exposure to different types of food might prevent the onset of sensory-specific satiety, that is defined as the decline in pleasure derived from consuming a known type of food in comparison to exposure to a new flavour or food (Rolls, Rolls, Rowe, \& Sweeney, 1981). This effect might be also attributed to habituation, as exposure to different types of foods might retard the habituation process (Temple, Giacomelli, Roemmich, \& Epstein, 2008). The variety effect in appetite has been demonstrated in both humans and animals (Bouton, Todd, Miles, León, \& Epstein, 2013; Temple et al., 2006). For example, in a previous work, researchers showed that food variety could change the rate of habituation in children involved in a food-seeking task (Temple et al., 2008). In a previous randomized 8-week behavioural weight loss intervention, limiting energy-dense food group variety across several days produced long-term sensory-specific satiety and monotony (Raynor, Niemeier, \& Wing, 2006).

Our study hypothesised a long-term influence of diet variety on appetitive traits of children. Overall, different levels of tracking of diet variety were associated with eating behaviours related to appetite at 7 years of age. Maintaining a high diet variety in childhood was inversely associated with problematic behaviours such as being a fussy eater. Children with a higher dietary variety also had a higher general interest in food although a lower desire to have drinks, and lower satiety responsiveness, than those with a low dietary variety. A lack of interest in food, including fussy eating, is being described as a common problem among children (Taylor, Wernimont, Northstone, \& Emmett, 2015). Increasing variety of healthy food could be a strategy to decrease eating problems among children. Previous research suggests that following a less healthy dietary pattern early in life increases the risk of disordered eating behaviours later in childhood (Albuquerque et al., 2016).

Strengths of this study are the longitudinal design based on a large population-based birth cohort, and the use of the same method to describe tracking of diet variety across childhood. We also analyzed the prospective association between tracking of diet variety and appetitive traits, overcoming the limitations of cross- 
sectional studies. However, we evaluated children's eating behaviours only at 7 years and we could not exclude a bidirectional association between diet variety and eating behaviours. It was previously described a bidirectional relationship between children's fussy behaviour and parents feeding practices (Jansen et al., 2017). The authors also suggested an increase of variety of foods offered to increase food acceptance, decreasing fussiness behaviour (Jansen et al., 2017). Parental concerns for problematic behaviours were used at 4 years as a proxy of previously eating behaviours.

Additional limitations of this study will be discussed. Our diet variety index was based on data of a short FFQ, which did not allow measuring variety of fruit and vegetable. A previous systematic review (Marshall et al., 2014) studied different diet indices in paediatric age, including those used to evaluate variety in diet related to health outcomes. The majority of FFQ used to create the several diet variety indices had less than 60 food items, with some studies using FFQ with less than 20 food items (Marshall et al., 2014). Adding more questions to the FFQ would help increase the accuracy of our diet variety index; however, that would increase the burden of response among caregivers, which could result in more losses to follow-up or more errors in the responses. Even with the short FFQ we were capable to find tracking in the diet variety and its associations with eating behaviours related to appetite. Eating behaviours were assessed subjectively through the CEBQ based on caregivers' report; however, the CEBQ subdimensions have shown a good internal reliability in this population (Albuquerque et al., 2017) and good correspondence with objective measures in previous studies (Carnell \& Wardle, 2007). Children's dietary intake was also based on reported by parents or caregiver who might not be aware of all the foods eaten by the child. Comparing FFQ with 3day food diaries, a fair to moderate agreement was obtained for those food items eaten more often. The trend for an overall decrease in diet variety could be explained by the effect of the regression to the mean, which is a statistical phenomenon that can happen when repeated measurements are made on the same participant over time (Barnett, van der Pols, \& Dobson, 2005). We quantified the regression to the mean effect in our sample, assuming the 3rd tertile of diet variety as the cut-off point. We found an estimated regression to the mean effect for the diet variety (0.19) much lower than the mean difference found in our sample $(-0.41,95 \% \mathrm{CI}: 0.39 ; 0.43)$. These data indicate that a decrease in diet variety from 4 to 7 years of age cannot be completely explained by this statistical phenomenon.

\section{Conclusions}

Children with a higher diet variety were less fussy, had a lower desire to drink and had a higher general interest in food. Although these eating behaviours related to appetite track throughout childhood, they can nevertheless be managed using strategies, such as having a variety of healthy foods consistently available at home and persisting with the provision of variety over time. Diet variety seems to decrease with age in childhood; these findings enhance the need of implementing effective strategies to increase the consumption of a variety of healthy foods, including fruit and vegetables, from early life.

\section{Acknowledgements}

The authors gratefully acknowledge the families enrolled in Generation XXI for their kindness, all members of the research team for their enthusiasm and perseverance and the participating hospitals and their staff for their help and support. The authors acknowledge the support from the Epidemiology Research Unit (EPI-Unit: UID-DTP/04750/2013).

\section{Appendix A. Supplementary data}

Supplementary data related to this article can be found at https://doi.org/10.1016/j.appet.2017.12.030.

\section{Potential conflict of interest and source of funding}

The authors declare no conflicts of interest.

Generation XXI was funded by the Health Operational Programme - Saúde XXI, Community Support Framework III and the Regional Department of Ministry of Health. It was supported by the Calouste Gulbenkian Foundation, by FEDER from the Operational Programme Factors of Competitiveness - COMPETE and through national funding from the Foundation for Science and Technology FCT (Portuguese Ministry of Education and Science) under the project PTDC/SAU-EPI/121532/2010 (FEDER-Operational Programme Factors of Competitiveness - COMPETE - FCOMP-01-0124FEDER-021177), and the PhD Grant SFRH/BD/92389/2013 (SV) cofunded by the FCT and the POPH/FSE Program; and the FCT Investigator contract (IF/01350/2015) (AO).

\section{References}

Albuquerque, G., Lopes, C., Durao, C., Severo, M., Moreira, P., \& Oliveira, A. (2016 Dec 02). Dietary patterns at 4 years old: Association with appetite-related eating behaviours in 7 year-old children. Clinical Nutrition. https://doi.org/10.1016/ j.clnu.2016.11.023. pii: S0261-5614(16)31340-1, [Epub ahead of print].

Albuquerque, G., Severo, M., \& Oliveira, A. (2017 Jan). Early life characteristics associated with appetite-related eating behaviors in 7-year-old children. The Journal of Pediatrics, 180, 38-46. e2.

Anzman-Frasca, S., Savage, J. S., Marini, M. E., Fisher, J. O., \& Birch, L. L. (2012 Apr). Repeated exposure and associative conditioning promote preschool children's liking of vegetables. Appetite, 58(2), 543-553.

Ashcroft, J., Semmler, C., Carnell, S., van Jaarsveld, C. H., \& Wardle, J. (2008 Aug). Continuity and stability of eating behaviour traits in children. European Journal of Clinical Nutrition, 62(8), 985-990.

Barnett, A. G., van der Pols, J. C., \& Dobson, A. J. (2005 Feb). Regression to the mean: What it is and how to deal with it. International Journal of Epidemiology, 34(1), 215-220.

de Barse, L. M., Jansen, P. W., Edelson-Fries, L. R., Jaddoe, V. W. V., Franco, O. H., Tiemeier, H., et al. (2017 Jul 1). Infant feeding and child fussy eating: The Generation R Study. Appetite, 114, 374-381.

Bjelland, M., Brantsaeter, A. L., Haugen, M., Meltzer, H. M., Nystad, W., \& Andersen, L. F. (2013 Aug 30). Changes and tracking of fruit, vegetables and sugar-sweetened beverages intake from 18 months to 7 years in the Norwegian Mother and Child Cohort Study. BMC Public Health, 13, 793.

Bouton, M. E., Todd, T. P., Miles, O. W., León, S. P., \& Epstein, L. H. (2013). Within- and between-session variety effects in a food-seeking habituation paradigm. Appetite, 66, 10-19 [Article].

Brondel, L., Romer, M., Van Wymelbeke, V., Pineau, N., Jiang, T., Hanus, C., et al. (2009 Apr 20). Variety enhances food intake in humans: Role of sensoryspecific satiety. Physiol Behav, 97(1), 44-51 [Clinical Trial].

Bucher, T., Siegrist, M., \& van der Horst, K. (2014 Jun). Vegetable variety: An effective strategy to increase vegetable choice in children. Public Health Nutrition, 17(6), $1232-1236$.

Burchi, F., Fanzo, J., \& Frison, E. (2011 Feb). The role of food and nutrition system approaches in tackling hidden hunger. Int J Environ Res Public Health, 8(2), 358-373 [Review].

Carnell, S., \& Wardle, J. (2007 Jan). Measuring behavioural susceptibility to obesity: Validation of the child eating behaviour questionnaire. Appetite, 48(1), 104-113 [Research Support, Non-U.S. Gov't validation Studies].

Cohen, J. A. (1992 Jul). Power primer. Psychological Bulletin, 112(1), 155-159.

Conklin, A. I., Monsivais, P., Khaw, K. T., \& Wareham, N. J. (2016 Jul). Dietary diversity, diet cost, and incidence of type 2 diabetes in the United Kingdom: A prospective cohort study. PLoS Medicine, 13(7), e1002085.

Cooke, L. (2007 Aug). The importance of exposure for healthy eating in childhood: A review. Journal of Human Nutrition and Dietetics, 20(4), 294-301.

Cox, D. R. Skinner, J. D., Carruth, B. R., Moran, J., 3rd, \& Houck, K. S. (1997 Dec). A food variety index for Toddlers (VIT): Development and application. Journal of the American Dietetic Association, 97(12), 1382-1386. quiz 7-8.

Durao, C., Andreozzi, V., Oliveira, A., Moreira, P., Guerra, A., Barros, H., et al. (2015 Sep). Maternal child-feeding practices and dietary inadequacy of 4-year-old children. Appetite, 92, 15-23.

Foote, J. A., Murphy, S. P., Wilkens, L. R., Basiotis, P. P., \& Carlson, A. (2004 Jul). Dietary variety increases the probability of nutrient adequacy among adults. Journal of Nutrition, 134(7), 1779-1785.

Jansen, P. W., de Barse, L. M., Jaddoe, V. W. V., Verhulst, F. C., Franco, O. H., \& Tiemeier, H. (2017 Jul 1). Bi-directional associations between child fussy eating 
and parents' pressure to eat: Who influences whom? Physiology \& Behavior, 176, $101-106$.

Jones, L., Moschonis, G., Oliveira, A., de Lauzon-Guillain, B., Manios, Y., Xepapadaki, P., et al. (2015 Jul). The influence of early feeding practices on healthy diet variety score among pre-school children in four European birth cohorts. Public Health Nutrition, 18(10), 1774-1784.

Landis, J. R., \& Koch, G. G. (1977 Mar). The measurement of observer agreement for categorical data. Biometrics, 33(1), 159-174 [Research Support, U.S. Gov't, NonP.H.S. Research Support, U.S. Gov't, P.H.S.].

Larsen, P. S., Kamper-Jorgensen, M., Adamson, A., Barros, H., Bonde, J. P., Brescianini, S., et al. (2013 Jul). Pregnancy and birth cohort resources in europe: A large opportunity for aetiological child health research. Paediatric \& Perinatal Epidemiology, 27(4), 393-414.

Madruga, S. W., Araujo, C. L., Bertoldi, A. D., \& Neutzling, M. B. (2012 Apr). Tracking of dietary patterns from childhood to adolescence. Revista de Saúde Pública, 46(2), 376-386.

Maier, A. S., Chabanet, C., Schaal, B., Leathwood, P. D., \& Issanchou, S. N. (2008 Dec), Breastfeeding and experience with variety early in weaning increase infants' acceptance of new foods for up to two months. Clinical Nutrition, 27(6), $849-857$.

Mallan, K. M., Fildes, A., Magarey, A. M., \& Daniels, L. A. (2016 Apr). The relationship between number of fruits, vegetables, and noncore foods tried at age 14 Months and food preferences, dietary intake patterns, fussy eating behavior, and weight status at age 3.7 years. Journal of the Academy of Nutrition and Dietetics, 116(4), 630-637.

Marshall, S., Burrows, T., \& Collins, C. E. (2014 Dec). Systematic review of diet quality indices and their associations with health-related outcomes in children and adolescents. Journal of Human Nutrition and Dietetics, 27(6), 577-598.

McCrory, M. A., Burke, A., \& Roberts, S. B. (2012). Dietary (sensory) variety and energy balance. Physiology \& Behavior, 107(4), 576-583.

Meengs, J. S., Roe, L. S., \& Rolls, B. J. (2012). Vegetable Variety: An effective strategy to increase vegetable intake in adults. Journal of the Academy of Nutrition and Dietetics, 112(8), 1211-1215.

Meengs, J. S., Roe, L. S., \& Rolls, B. J. (2012 Aug). Vegetable variety: An effective strategy to increase vegetable intake in adults. Journal of the Academy of Nutrition and Dietetics, 112(8), 1211-1215.

Mikkila, V., Rasanen, L., Raitakari, O. T., Pietinen, P., \& Viikari, J. (2004 Jul). Longitudinal changes in diet from childhood into adulthood with respect to risk of cardiovascular diseases: The Cardiovascular Risk in Young Finns Study. European Journal of Clinical Nutrition, 58(7), 1038-1045.

Mikkila, V., Rasanen, L., Raitakari, O. T., Pietinen, P., \& Viikari, J. (2005 Jun). Consistent dietary patterns identified from childhood to adulthood: The cardiovascular risk in young finns study. British Journal of Nutrition, 93(6), 923-931.

Murphy, S. P., Foote, J. A., Wilkens, L. R., Basiotis, P. P., Carlson, A., White, K. K., et al. (2006 Mar). Simple measures of dietary variety are associated with improved dietary quality. Journal of the American Dietetic Association, 106(3), 425-429.

Nicklaus, S. (2009 Feb). Development of food variety in children. Appetite, 52(1), 253-255.

Nicklaus, S., Boggio, V., Chabanet, C., \& Issanchou, S. (2005 Jun). A prospective study of food variety seeking in childhood, adolescence and early adult life. Appetite, 44(3), 289-297.

Northstone, K., \& Emmett, P. M. (2008 Nov). Are dietary patterns stable throughout early and mid-childhood? A birth cohort study. British Journal of Nutrition, 100(5), 1069-1076.

Oliveira, A., Jones, L., de Lauzon-Guillain, B., Emmett, P., Moreira, P., Charles, M. A., et al. (2015 Sep 14). Early problematic eating behaviours are associated with lower fruit and vegetable intake and less dietary variety at 4-5 years of age. A prospective analysis of three European birth cohorts. British Journal of Nutrition, 114(5), 763-771.

Ramsay, S. A., Shriver, L. H., \& Taylor, C. A. (2017 Mar). Variety of fruit and vegetables is related to preschoolers' overall diet quality. Preventive Medicine Reports, 5,
$112-117$.

Rauber, F., Hoffman, D. J., \& Vitolo, M. R. (2014 Feb). Diet quality from pre-school to school age in brazilian children: A 4-year follow-up in a randomised control study. British Journal of Nutrition, 111(3), 499-505.

Raynor, H. A., \& Epstein, L. H. (2001 May). Dietary variety, energy regulation, and obesity. Psychological Bulletin, 127(3), 325-341.

Raynor, H. A., Niemeier, H. M., \& Wing, R. R. (2006 Jan). Effect of limiting snack food variety on long-term sensory-specific satiety and monotony during obesity treatment. Eating Behaviors, 7(1), 1-14.

Remington, A., Anez, E., Croker, H., Wardle, J., \& Cooke, L. (2012 Jan). Increasing food acceptance in the home setting: A randomized controlled trial of parentadministered taste exposure with incentives. American Journal of Clinical Nutrition, 95(1), 72-77.

Roe, L. S., Meengs, J. S., Birch, L. L., \& Rolls, B. J. (2013 Sep). Serving a variety of vegetables and fruit as a snack increased intake in preschool children. American Journal of Clinical Nutrition, 98(3), 693-699.

Rolls, B. J., Rolls, E. T., Rowe, E. A., \& Sweeney, K. (1981 Jul). Sensory specific satiety in man. Physiology \& Behavior, 27(1), 137-142.

Salehi-Abargouei, A., Akbari, F., Bellissimo, N., \& Azadbakht, L. (2016 Jan). Dietary diversity score and obesity: A systematic review and meta-analysis of observational studies. European Journal of Clinical Nutrition, 70(1), 1-9.

Skinner, J. D., Carruth, B. R., Bounds, W., Ziegler, P., \& Reidy, K. (2002 Nov-Dec). Do food-related experiences in the first 2 years of life predict dietary variety in school-aged children? Journal of Nutrition Education and Behavior, 34(6), $310-315$.

Steyn, N. P., Nel, J. H., Nantel, G., Kennedy, G., \& Labadarios, D. (2006 Aug). Food variety and dietary diversity scores in children: Are they good indicators of dietary adequacy? Public Health Nutrition, 9(5), 644-650.

Taylor, C. M., Wernimont, S. M., Northstone, K., \& Emmett, P. M. (2015 Dec). Picky/ fussy eating in children: Review of definitions, assessment, prevalence and dietary intakes. Appetite, 95, 349-359.

Temple, J. L., Giacomelli, A. M., Roemmich, J. N., \& Epstein, L. H. (2008 Mar-May). Habituation and within-session changes in motivated responding for food in children. Appetite, 50(2-3), 390-396.

Temple, J. L., Kent, K. M., Giacomelli, A. M., Paluch, R. A., Roemmich, J. N., \& Epstein, L. H. (2006). Habituation and recovery of salivation and motivated responding for food in children. Appetite, 46(3), 280-284.

U.S. Department of Agriculture, \& U.S. Department of Health and Human Services. (2010). Dietary guidelines for americans (7th ed.). Washington, DC: U.S. Government Printing Office.

Vadiveloo, M., Dixon, L. B., \& Parekh, N. (2013 May). Associations between dietary variety and measures of body adiposity: A systematic review of epidemiological studies. British Journal of Nutrition, 109(9), 1557-1572.

Vadiveloo, M., Parkeh, N., \& Mattei, J. (2015 Mar). Greater healthful food variety as measured by the US healthy food diversity index is associated with lower odds of metabolic syndrome and its components in US adults. Journal of Nutrition, 145(3), 564-571.

Wardle, J., Guthrie, C. A., Sanderson, S., \& Rapoport, L. (2001 Oct). Development of the Children's eating behaviour questionnaire. J Child Psychol Psychiatry, 42(7), 963-970 [Research Support, Non-U.S. Gov't Validation Studies].

WHO. (1996). Preparation and use of food-based dietary guidelines. WHO Technical Report, Series 880. Report of a Joint FAO/WHO Consultation. Geneva, Switzerland: World Health Organization.

WHO European Region. (2003). Food based dietary guidelines in the WHO European Region. Copenhagen: WHO. Europe.

WHO Multicentre Growth Reference Study Group. (2006). WHO Child Growth Standards: Length/height-for-age, weight-for-age, weight-for-length, weight-forheight and body mass index-for-age: Methods and development. Geneva.

Wijnhoven, H. A., van der Meij, B. S., \& Visser, M. (2015 Dec). Variety within a cooked meal increases meal energy intake in older women with a poor appetite. Appetite, 95, 571-576. 